\title{
Degradation and Stabilization of Poly(Butylene Adipate-Co-Terephthalate)/Polyhydroxyalkanoate Biodegradable Mulch Films Under Different Aging Tests
}

\author{
Yuchuan Tian \\ Sinopec Shanghai Research Institute of Petrochemical Technology \\ James Wang ( $\sim$ JamesWang.sshy@sinopec.com ) \\ Sinopec Shanghai Research Institute of Petrochemical Technology \\ Bing Zhou \\ Shanghai Research Institute of Petrochemical Technology
}

\section{Research Article}

Keywords: Biodegradable mulch films, PBAT/PHA blends, accelerated aging test, degradation, twin screw extrusion

Posted Date: April 13th, 2021

DOI: https://doi.org/10.21203/rs.3.rs-398859/v1

License: (c) (1) This work is licensed under a Creative Commons Attribution 4.0 International License. Read Full License

Version of Record: A version of this preprint was published at Journal of Polymers and the Environment on September 7th, 2021. See the published version at https://doi.org/10.1007/s10924-021-02279-z. 


\section{Abstract}

The degradation and stability of biodegradable films determine the service length of mulch films in actual use. Most biodegradable polymers degrade too fast to meet the required durability of mulch films. The objective of this work is to investigate the degradation behaviors of poly(butylene adipate-coterephthalate) (PBAT) /polyhydroxyalkanoate (PHA) blend mulch films. Several different types of stabilizers were incorporated in the biodegradable blends to provide protection for the PHA/PBAT films during thermal processing and aging on agricultural fields. The degradation process of the films was systematically studied under an Accelerated Aging Test (AAT) and a Soil Aging Test (SAT). Adding a light stabilizer, UV stabilizer, or antioxidant to the mulch films led to significant improvement in the retention of mechanical properties of the films under both AAT and SAT. Morphological evolution of the films with or without a UV stabilizer as a function of aging times was studied by Scanning Electron Microscopy (SEM). The results of thermal properties and crystallinity revealed damage of crystal structure of the films during AAT. Spectrocopic results indicated that the films underwent both hydrolysis and photodegradative chain scissions (Norrish Type I/II reactions and photo-oxidation). The degradation mechanisms of the PHA/PBAT biodegradable mulch films were proposed.

\section{Introduction}

Plastic mulch films have contributed to improving crop yields by increasing soil temperature, reducing water loss, and limiting weed growth, etc. [1], use of mulch films is especially important for arid regions around the world. However, the polymers used in commercial mulch films are not biodegradable, polyolefins (PO) [2], ethylene-vinyl acetate (EVA), and polyvinyl chloride (PVC) [3] are the most common polymers used in manufacturing mulch films. As these polymer films remain intact after crop harvesting, and due to the high cost of film collection, these mulch films are typically plowed into soil as plastic fragments.

Over time, plastic film residues in soil get accumulated to a level which starts to affect seed germination and crop growth, causing environmental problems for sustainable use of farmland [4]. As a result, there is a growing need to develop biodegradable mulch films which can provide the mulch functions during the crop growth but get biodegraded within a crop planting cycle. This has led to significant interest from both industrial and academic scientists to investigate material options to create biodegradable mulch films.

Polyhydroxyalkanoates (PHA) are emerging biodegradable materials after research and development of several decades [5-7], they are accumulated intracellularly in cells by various microorganisms via microbial fermentation [8-10], using renewable carbon resources as feedstocks such as sugars, vegetable oils, etc. [11-13]. One of the advantages of PHA is their ease to biodegradation in a variety of environments including compost, soil or aquatic media, etc. Another advantage of PHA is that there are many PHA copolymers available to tailor their properties for different applications. 
However, several challenges still remain for using PHA for wide range of commercial applications. PHA have narrow processing window and they are prone to thermal degradation during film extrusion [11]. Efforts were made to improve the thermal and mechanical performance of PHA, mainly by blending with nanofillers and other polymers, or by designing PHA's polymeric structures [13-18].

Particularly, extensive studies were recently reported about blending PHA with poly(butylene adipate-coterephthalate) (PBAT) [19-24]. PBAT is a biodegradable aliphatic-aromatic copolyester which has excellent tensile strength and toughness [25]. Javadi et.al. blended poly(3-hydroxybutyrate-co-3hydroxyvalerate) (PHBV), a PHA copolymer, with PBAT though microcellular and conventional injection molding, resulted in significantly improved specific toughness [20].

Besides film performance, a key challenge for biodegradable mulch films is to improve their durability in soil to meet required service length for crop farming [26]. Enormous efforts were made to study the degradation of biodegradable materials [6, 24, 26-32]. There are two major degradation pathways for mulch films in use: (1) photodegradation, and (2) biodegradation.

When exposed to intensive sunlight, the mulch films, usually composed of polyesters, tend to become brittle, form cracks and holes, before finally disintegrate into small flakes [26]. Adding UV stabilizers could efficiently depress photodegradation process under UV exposure [33-35]. Zhu et al. synthesized a new type of UV stabilizer, the UV-SiO ${ }_{2}$ modified PBAT films exhibited much improved mechanical strength under UV exposure [34]. Souza et al. studied the addition of two combinations of light stabilizers to prevent photodegradation of PBAT mulch films under accelerated aging test [35].

However, there are only few studies focusing on photodegradation of PHA related mulch films [36, 37]. Scarfato et al. improved the tensile behaviors of PHBV/PBAT films by adding natural and organomodified halloysite nanofillers under accelerated test [36]. Mosnáčková et.al studied the natural aging of PLA/PHA mulch films with 3 wt.\% carbon black after application for one season under different conditions [37], however, the effect of stabilizers on improving UV stability was not addressed in their work.

In this work, there are two main objectives: (1) to understand the photodegradation process of PBAT/PHA mulch films under an accelerated aging test, and to explore the feasibility of using this accelerated test to predict degradation in soil, (2) to determine which stabilizer is the most effective in extending the use life of PBAT/PHA films in mulch film applications. Specifically, three different kinds of stabilizers: an antioxidant, a UV stabilizer, and a hydrolysis resistance additive were evaluated. The PBAT/PHA mulch films were prepared from melt blends made by a twin screw extrusion process. The degradation process of PBAT/PHA films was systematically studied by different characterization and test methods (DSC, XRD, ATR-FTIR, XPS, SEM, and tensile testing).

\section{Experimental Section}




\subsection{Materials}

Poly(3-hydroxybutyrate-co-4-hydroxybutyrate) (P3HB/4HB) was produced by bacterial fermentation and it was supplied by Tianjin Green Bioscience Co., Ltd. (Tianjin, China), it is a random PHA copolymer having $10 \mathrm{~mol} . \%$ of $4 \mathrm{HB}$ and $90 \mathrm{~mol} . \%$ of $3 \mathrm{HB}$, its number average molecular weight $\left(M_{n}\right)$ is $3.68 \times 10^{5} \mathrm{~g} / \mathrm{mol}$ (measured by GPC). Poly(butylene adipate-co-terephthalate) (PBAT) (Grade: C1200) was purchased from BASF (Ludwigshafen, German). 2(2'-Hydroxy-3',5'-di-t- butylphenyl)-5-Chloro-benzo-triazole (designated as UVA) was used as an UV absorber and it was supplied by Yixing Tianshi Chemicals Co., Ltd. (Yixing, China). Pentaerythitol tetrakis-3-(3,5-di-t-butyl-4-hydroxyphenyl)-propionate (designated as AO) was used as an antioxidant, it was supplied by King Chemical Co., Ltd. (Shanghai, China). The carbodiimide (designated as HA) HyMax ${ }^{\circledR} 1010$ was used as a hydrolysis resistance additive, it was purchased from Langyi Functional Materials Co., Ltd. (Shanghai, China). An oligomeric chain extender Joncryl ADR4370F was purchased from BASF (Ludwigshafen, German).

\subsection{Preparation of PBAT/PHA films}

PBAT and PHA and were dried in vacuum oven for 2 hours before use, PBAT/PHA composite pellets were prepared by melt extrusion on a twin screw extruder with a diameter of $20 \mathrm{~mm}$ and L/D of 40/1 (Micro 27, LabTech Scientific Twin Screw Lab Extruder). In a typical extrusion experiment, a mixture of PBAT and PHA with a weight ratio of 80:20, along with 0.5 wt.\% chain extender and specific amount of stabilizers, was added to the feed section of the extruder. The temperatures of extruder for zones 1 to 11 were set to: $135^{\circ} \mathrm{C}, 145^{\circ} \mathrm{C}, 165^{\circ} \mathrm{C}, 170^{\circ} \mathrm{C}, 175^{\circ} \mathrm{C}, 175^{\circ} \mathrm{C}, 175^{\circ} \mathrm{C}, 175^{\circ} \mathrm{C}, 175^{\circ} \mathrm{C}, 175^{\circ} \mathrm{C}$, and $170^{\circ} \mathrm{C}$, and screw speed was $200 \mathrm{rpm}$. The extruded PBAT/PHA blend strands were cut into pellets which were subsequently dried in a vacuum oven for 2 hours and stored in sealed bags. For details, see supplemental Table S1.

PBAT/PHA films were prepared by adding the PBAT/PHA blends (in pellet form) to the feeding zone of a Collin single-screw extruder (screw diameter: $19 \mathrm{~mm}$, L/D: 25/1) fitted with a blown film die having a diegap of $0.8 \mathrm{~mm}$. The temperatures of the extruder were set to $50^{\circ} \mathrm{C}, 175^{\circ} \mathrm{C}, 175^{\circ} \mathrm{C}, 180^{\circ} \mathrm{C}$, and $170^{\circ} \mathrm{C}$ from its feed zone to die, screw speed was $30 \mathrm{rpm}$, film was drawn at speed of $6 \mathrm{~m} / \mathrm{s}$. The thickness of films ranged from 13 to $20 \mu \mathrm{m}$, detailed process conditions are listed in Table S2. The average film thickness was calculated from data measured at 5 different locations on each film sample.

\subsection{Degradation test}

In the accelerated aging test (AAT), PBAT control and different PBAT/PHA films were exposed to UV light in a Xenon Test Chamber (Model: Q-SUN Xe-3, Q-Lab Corporation, Cleveland, Ohio, USA). Its irradiance was $0.51 \mathrm{~W} / \mathrm{m}^{2}$ at a wavelength of $340 \mathrm{~nm}$. The temperature inside of the chamber was $38^{\circ} \mathrm{C}$, and the humidity was kept at $50 \%$. In a typical test, four samples were placed on fixed aluminum holders in the chamber. The inside surface of the chamber was made from highly reflective aluminum. To simulate 
mulching conditions, the films were exposed to repeating cycles of UV light for 108 minutes, and then followed by spraying water for 18 minutes to mimic the effects of hydrolysis resulting from rain fall. At each additional 24 hours, a piece of film was cut from each film sample for characterizations of samples after AAT at the time period.

\subsection{Soil degradation test}

The soil degradation tests of mulch films were performed by placing mulch films on soil (leached noncalcareous soils, Shanghai) in flower pots from October to November of 2019, placed in an unshaded area, in Pudong New District, Shanghai, China. The mulch films tested were $50 \times 50 \mathrm{~cm}^{2}$ squares. A piece of film was cut from the film samples after every 7 days for property tests. In order to keep the soil moist, an adequate amount of water was added to each pot every 3 days. Typically, at least 3 different film samples were tested for each film to achieve a good reproducibility.

\subsection{Characterization}

Differential scanning calorimetry (DSC) was conducted on a DISCOVERY DSC FC100 with a refrigerated cooling system Model 90, supplied by Thermal Analysis, New Castle, USA. A sample of about $7 \mathrm{mg}$ was first kept at $40^{\circ} \mathrm{C}$ and then heated to $220^{\circ} \mathrm{C}$ at a heating rate of $10^{\circ} \mathrm{C} / \mathrm{min}$ under a flow of nitrogen, it was then cooled down to $-50^{\circ} \mathrm{C}$ at a rate of $10^{\circ} \mathrm{C} /$ min during the first cooling cycle, followed by heating to $220^{\circ} \mathrm{C}$ at a heating rate of $10^{\circ} \mathrm{C} / \mathrm{min}$.

Attenuated total reflection FTIR (ATR-FTIR) spectra were recorded on a Frontier FTIR spectrometer with a universal ATR sampling accessory, supplied by PerkinElmer, Waltham, MA, USA.

X-ray photoelectron spectroscopy (XPS) spectra were collected using a Kratos Axis Ultra DLD with a monochomatic aluminum Ka light source at room temperature.

Wide angle X-Ray diffraction (WAXRD) analysis was performed using Scintag XDS-2000 with Ni-filtered Cu Ka radiation $\left(1.5418 \AA\right.$ ) at room temperature in the range of $2 \theta=1.5-40^{\circ}$ with a scanning rate of $2 \%$ min.

Scanning electron microscopy (SEM) was conducted on a ZEISS Merlin electron microscope with an acceleration voltage of $2 \mathrm{kV}$ and the working distance of $5 \mathrm{~mm}$.

Tensile tests were performed on an Instron 3344 testing system, supplied by Instron-USA, Norwood, MA, USA, according to ISO 527-3-2018. Tensile tests of the films were performed at a grip distance of $50 \mathrm{~mm}$, a testing rate of $100 \mathrm{~mm} / \mathrm{min}$, and a specimen width of $15 \mathrm{~mm}$. All the film samples were stored in a constant humidity chamber at a temperature $23^{\circ} \mathrm{C}$ and a relative humidity of $60 \%$ for 24 hours before tests. 


\section{Results And Discussion}

\subsection{Retention of mechanical properties under accelerated aging tests (AAT)}

The PBAT/PHA films were made from polymer blends prepared by a twin screw extrusion process, the films contain $80 \mathrm{wt} . \%$ PBAT and 20 wt.\% PHA with or without stabilizing additives. The mechanical properties of these films before Accelerate Aging Test (AAT) are listed in Table 1. The data showed that adding a UV stabilizer (UVA) or a hydrolysis resistance additive (HA) to PBAT/PHA films slightly decreased both tensile strength $(\sigma)$ and elongation at break $\left(\varepsilon_{b}\right)$ of the biodegradable films, while adding an antioxidant (AO) led to a significant increase in tensile strength of the film (from $18 \mathrm{MPa}$ to $35 \mathrm{MPa}$ ), which could be attributed to decreased thermal degradation of the film in the presence of the antioxidant during the melt extrusion blending process and subsequent film extrusion.

The retention ratios of mechanical properties of PBAT, PBAT/PHA, and PBAT/PHA with different additives under AAT are summarized in Table 1.

Table 1. Mechanical properties of PBAT/PHA films before AAT

\begin{tabular}{|llllll|}
\hline Film Samples & PBAT & PBAT/PHA & $\begin{array}{l}\text { PBAT/PHA } \\
+ \text { PVA }\end{array}$ & $\begin{array}{l}\text { PBAT/PHA } \\
+ \text { AO }\end{array}$ & $\begin{array}{l}\text { PBAT/PHA } \\
+ \text { HA }\end{array}$ \\
\hline Tensile strength (MPa) & 26 & 18 & 21 & 35 & 16 \\
\hline Elongation at break $(\%)$ & 607 & 603 & 521 & 618 & 472 \\
\hline
\end{tabular}

The effects of adding PHA to PBAT on film properties are shown as Figs. $1 \mathrm{a}$ and $1 \mathrm{~b}$, the presence of only $20 \%$ PHA caused a sharp decrease in both the elongation at break and the tensile strength of PBAT/PHA film, as compared to pure PBAT film. A 77\% reduction in elongation and $39 \%$ reduction in tensile strength were found respectively at $72 \mathrm{~h}$. However, the difference became smaller at $100 \mathrm{~h}$. The results suggest that PHA is more easily degradable than PBAT under the repeated UV exposure and water spray cycles under AAT conditions, this is in agreement with a previous study which found PHA degraded faster than other polymers in accelerated soil degradation [38]. This difference could be due to the fully aliphatic backbone of PHA versus aliphatic and aromatic copolymer backbone of PBAT as shown in Figure 2 . Nevertheless, this also emphasizes the importance to stabilize PHA-containing PBAT blends in order to meet durability requirements for mulch film applications.

The retention behaviors of PBAT/PHA film as a control and thee PBAT/PHA films with stabilizing additives during AAT are shown as Figs. $1 \mathrm{c}$ and $1 \mathrm{~d}$. Adding an antioxidant (AO) and a hydrolysis resistance additive $(\mathrm{HA})$ to the films apparently did not contributed to films' stability at a short test time (e.g. 24 h.), however, these additives did provide stabilizing effects for elongation retention at extended exposure times (>48 h.), which showed 16\%-24\% improvement over the film without these additives. 
This could be attributed to the fact that an antioxidant only reacts with peroxyl radical generated during oxidation [39-41], and hydrolysis resistance additive only reacts with carboxyl group generated during hydrolysis of the biodegradable polymers [42]. In the early stage of UV-induced photodegradation process, it is reasonable to assume that neither peroxyl radical nor carboxyl group are generated in sufficient amount for them to react with an antioxidant or a hydrolysis resistant additive. As a result, both $\mathrm{AO}$ and $\mathrm{HA}$ are only effective in improving the films' stability after a relatively longer aging period, when more peroxyl radical and carboxyl group are produced in the films.

Among all the additives tested, the most effective stabilizer is the UV stabilizer, i.e. UVA. The $\varepsilon_{\mathrm{b}}$ decrease of the PBAT/PHA-UVA film was significantly less than the other thee films, and it retained the highest $\varepsilon_{\mathrm{b}}$ $(46 \%)$ at $100 \mathrm{~h}$. The retention of tensile strength of the PBAT/PHA-UVA film was also the best among all the films as well. The UV stabilizer in PBAT/PHA films can absorb UV radiation energy and undergo structural transformation [43] to provide a stabilizing effect. The above results demonstrated the importance of incorporating a UV stabilizer to provide protection against UV irradiation for the films.

\subsection{Morphology change under AAT}

The surface morphology images of PBAT/PHA films at different aging times were studied by SEM. In Fig. $3 a$, the surface of PBAT/PHA film before aging was smooth with clear orientation marks along the machine direction formed during blown film process. The orientation helps to improve mechanical properties of films [44, 45]. After 24 hours of aging, as shown in Fig. 3b, the surface began to show some roughness, some small protrusions appeared on surface, which may be formed after partial surface degradation of the film and degraded material was washed away by sprayed water. After 72 hours of accelerated aging (Fig. 3c), several small cavities can be clearly observed on the surface. Surprisingly, a large hole with a diameter of approximately $10 \mu \mathrm{m}$ (in Fig. 3d), was formed at $100 \mathrm{~h}$.

As a result, it seemed that due to UV irradiation, the surface of PBAT/PHA film underwent partial erosion of the outer layer at first, followed by formation of small cavities, and finally large cavities were formed. Also, it is noticed that surface orientation of PBAT/PHA became less distinct after aging, which may be due to the gradual destruction and wash away of the surface layer after extended UV exposure.

For comparison, the SEM images of PBAT/PHA-UVA at different aging times are shown in Fig. 4. After 24 hours of aging, there were no significant defects or holes observed on the surface (Fig. 4b). After 72 hours, the surface started to appear coarse (Fig. 4c). Moreover, surface orientation became less distinct for PBAT/PHA-UVA after $100 \mathrm{~h}$ aging, but still no formation of cavities or large holes were observed.

As a result, it can be concluded that adding UVA can effectively slow down the photodegradation process for PBAT/PHA films. As a result, the PBAT/PHA-UVA had a much higher retention of $\varepsilon_{b}$ after 100 hours of accelerated aging as compared to all other additives. 


\subsection{Thermal properties and crystalline structures}

The thermal properties of PBAT/PHA films before and after AAT were studied by DSC. In Figs. 5A and 5B, as aging time increases from 0 to $50 \mathrm{~h}$ and $100 \mathrm{~h}$, both the crystallization temperature $\left(T_{C}\right)$ and melting temperature $\left(T_{m}\right)$ of PBAT component in PBAT/PHA films shifted to lower temperatures, indicating a decrease of crystal size [34], the peaks also lost sharpness and became broader than the peak at $0 \mathrm{~h}$. This could be resulted from chain scission taking place during the photodegradation process in AAT, PBAT tends to partially transform from ordered crystalline structure to amorphous form.

Moreover, after 100 hours of aging, the most significant broadening of $T_{C}$ peak was observed, and this also provides support for chain scission could have happened during degradation. This is in agreement with a study by Souza et. al. [35], they reported that chain scission in the photodegradation process was predominant in PBAT while studying accelerated aging of PBAT films with added carbon black and light stabilizers.

For the PBAT/PHA film with 0.5\% UV stabilizer (Fig. $5 \mathrm{c}$ ), the $\mathrm{T}_{\mathrm{c}}$ peak location and shape only had slight changes. This shows the UV stabilizer provided protection for PBAT/PHA against chain scission under UV radiation.

The quantitative changes of crystallization peak temperatures $\left(T_{c}\right)$ of PBAT, PBAT/PHA, and PBAT/PHA films with different stabilizers as a function of aging time are summarized in Fig. 6. Fig. 6a shows that adding $20 \%$ PHA to PBAT caused pronounced decreases of $T_{c}$ as compared to pure PBAT, i.e. making PBAT more prone to photodegradation. This could be resulted from the PHA degradation products having carboxyl groups at chain ends, the acidic carboxyl groups would have a catalytic or accelerating on the hydrolytic degradation of PBAT.

Fig. $6 \mathrm{~b}$ shows the relative effects of different additives on protecting PBAT/PHA films from photodegradation. The data proved that the different types of additives all had positive effects on protecting the polymers under UV radiation. The change in $T_{C}$ of PBAT/PHA with UV stabilizer (UVA) was the least, providing the best protection among the three additives, a similar effect was also reported in a previous finding [46]. For the PBAT/PHA films with antioxidant and hydrolysis resistant additives, the $\mathrm{T}_{\mathrm{C}}$ firstly decreased from 0 to $48 \mathrm{~h}$ aging, and then it kept relatively unchanged. Interestingly, this trend of $T_{C}$ is similar to the trend of mechanical properties discussed in the Section 3.1, where $\varepsilon_{b}$ of PBAT/PHA films with $\mathrm{AO}$ and $\mathrm{HA}$ additives initially decreased and then remained relatively unchanged.

In order to further study the crystallinity change of PBAT/PHA films after photodegradation, X-ray diffraction (XRD) analysis was performed and the results are shown in Fig. 7. There are three distinct diffraction peaks at $22.5^{\circ}, 23.4^{\circ}$, and $25.2^{\circ}$ respectively, which coincides with the characteristic diffraction peaks of PBAT (shown in Fig. S1) [47]. These were attributed to the Phase II crystals as reported by Chen [48]. For aging from 0 to 48 hours, the diffraction peaks of PBAT/PHA films remained relatively stable. However, after $100 \mathrm{~h}$ of aging, the intensities all thee specific diffraction peaks were 
drastically reduced. This indicates that under accelerated aging test, a large fraction of crystalline region of PBAT in PBAT/PHA films was transformed into amorphous region.

In comparison, the intensities of diffraction peaks of PBAT/PHA film with the UVA additive remained almost unchanged after 24,48 and $100 \mathrm{~h}$ of aging (Fig. $7 \mathrm{~b}$ ), however, the peak location of the peaks were shifted slightly to the right by $0.19^{\circ}$ after $100 \mathrm{~h}$ of aging.

The crystallinity study provides a structural interpretation for the trend of mechanical properties previously discussed. The results strongly support that the deterioration of the mechanical properties of PBAT/PHA films after accelerated aging is closely related to the change of crystallinity of PBAT in the films. Nevertheless, it should be noted that the change of crystalline structure during degradation is highly dependent on the backbone structure of polymer involved. For example, crystallinity of PLA film actually increased after degradation $[42,49]$.

\subsection{FT-IR and XPS spectroscopy}

ATR-FTIR helps to provide more structural information for studying the photodegradation mechanism of PBAT/PHA films. As shown in Fig. 8a, the intensities of multiple bands of ester groups decreased after degradation. In particular, $\mathrm{C}=0$ stretch band is found at $1710 \mathrm{~cm}^{-1}$ [26], and $\mathrm{C}-\mathrm{O}$ stretch bands are located at $1269 \mathrm{~cm}^{-1}$ and $1019 \mathrm{~cm}^{-1}[36,40]$. The observed weakening of these thee bands indicates breaking of ester groups during photodegradation. Meanwhile, as shown in Fig. $8 \mathrm{~d}$, the intensity of bands at $1685 \mathrm{~cm}^{-}$ 1 and $3435 \mathrm{~cm}^{-1}$ slightly increased, which belong to stretch absorption of carboxyl and hydroxyl groups of PHA respectively [39]. This provides evidence that hydrolysis happened during the photodegradation. The band at $667 \mathrm{~cm}^{-1}$ assigned to stretch vibration of $\mathrm{C}=\mathrm{C}-\mathrm{H}[46]$ increased after degradation (Fig. 8b). Moreover, the intensity of bands from 1578 to $1654 \mathrm{~cm}^{-1}$ due to $C=C$ stretching [50] also increased. The increase of these bands suggests formation of $\mathrm{C}=\mathrm{C}$ structures, which is typical of Norrish II photodegradation mechanism [51-53].

As a comparison, the FTIR spectra of PBAT/PHA with UV stabilizer before and after aging are shown as Fig. 8e. The respective bands did exhibit significant changes after AAT, indicating that the presence of the UV stabilizer in PBAT/PHA film has significantly improved the stability of the film during photodegradation process.

The $\mathrm{C}$ 1s XPS spectra of different PBAT/PHA films before and after AAT are shown in Fig. 9 to provide an in-depth understanding of the carbon binding states on the films' surface. Detailed information on the deconvoluted peaks of $\mathrm{C} 1 \mathrm{~s}$ is summarized in Table S3. For the PBAT/PHA film without additive (Fig. 9a and $9 \mathrm{~b}$ ), the $\mathrm{sp}^{2}$ carbon calculated from fitted curve increased from $26.7 \%$ before AAT to $36.3 \%$ after AAT, while the $\mathrm{sp}^{3}$ carbon decreased from $53.1 \%$ (before AAT) to $41.1 \%$ (after AAT). This suggests that about $10 \% \mathrm{sp}^{3}$ carbon transformed to $\mathrm{sp}^{2}$ carbon during the photodegradation process, providing evidence supporting the Norrish II [50] photodegradation mechanism for PBAT/PHA film without additive. 
The amount of $\mathrm{C}=0$ increased from $6.5 \%$ before AAT to $10 \%$ after AAT. This could be resulted from a photo-oxidation process which involves a classical hydrogen abstraction typically at a tertiary carbon in a-position of an ester group on a polymeric backbone, leading to formation of macroradicals $[49,54,55]$ (see scheme 1).

For the PBAT/PHA film with the UVA additive (Figs. $9 \mathrm{C}$ and 9D), amazingly, the $\mathrm{sp}^{3}$ carbon only decreased slightly from $47.4 \%$ before AAT to $46.8 \%$ after AAT, while C=0 increased moderately from $9.4 \%$ to $12.4 \%$ before and after AAT, respectively. This indicates that adding UVA has effectively inhibited photodegradation and provided protection to PBAT and PHA during AAT.

\subsection{Degradation mechanism of PBAT/PHA under AAT}

There were basically two degradation mechanisms in the literature proposed for biodegradable polyesters under a UV accelerated test: 1) photo-oxidative reactions, and 2) Norrish I/II type photodegradative reactions. The photo-oxidation mechanism was widely used to explain PLA (polylactic acid) degradation under UV exposure [54-56]. J. Rychlý [55] discussed that the tertiary carbon in PLA is the predominant site for oxidation, which is the most unstable carbon as compared to primary and secondary carbons when reacting with a hydroperoxy radical.

Since the PHA used in this work is a poly(3-hydroxybutyrate-4-hydroxybutyrate) (P3HB4HB) and it is composed of $90 \%$ of $3 \mathrm{HB}$ and $10 \%$ of $4 \mathrm{HB}$ units (Fig. 1), the tertiary carbon in $3 \mathrm{HB}$ is most likely to undergo photo-oxidative reactions as illustrated in Scheme 1. This may also provide a mechanistic basis for the observed much worse deterioration of mechanical properties of PBAT/PHA film than PBAT film under UV exposure during AAT, the reactive tertiary carbon in $4 \mathrm{HB}$ of PHA led to extensive photo-oxidation of PBAT/PHA and this causes the mechanical properties to significantly decrease.

As shown in Scheme 1, the hydrogen at the tertiary carbon is abstracted by an alkyl radical, which further reacts with oxygen to form a peroxy radical, followed by coupling with hydrogen abstraction forming a hydroperoxide and then cleaving the $0-\mathrm{C}$ bond, and this breaks a PHA chain into two separate chains, one chain has a carboxylic acid chain end and the other chain has a methyl-keto chain end. This process generates one more carbonyl group which accounts for the increased $\mathrm{C}=0$ level as observed on the XPS of PBAT/PHA film after subjecting to AAT test.

Beside the photo-oxidation for 3HB of PHA, the Norrish I and II type degradative reactions can also occur on polymer chains under an accelerated UV test [35, 49,57]. As illustrated in Scheme 2, for the butylene terephthalate structure of PBAT, the Norrish type II reaction can produce $\mathrm{C}=\mathrm{C}$ bond as a terminal vinyl group after a chain is cleaved, this accounts for the increased $\mathrm{Sp}^{2}$ carbon level after degradation from the XPS results. The Norris I type reactions occur around the aromatic carboxyl ester group in three possible chain scission reactions, forming different chain end structures and even $\mathrm{CO}_{2}[52]$. 


\subsection{Soil degradation test}

In the AAT test results discussed above, adding a UV stabilizer to PBAT/PHA film was shown to effectively reduce degradation under UV accelerated aging test conditions. A soil degradation test was carried out to test the effectiveness of different stabilizers for up to 30 days. The elongation at break $\left(\varepsilon_{\mathrm{b}}\right)$ retention results and tensile strength at break $\left(\sigma_{b}\right)$ are presented in Fig. 10.

It clearly showed that the UV stabilizer is effective to protect the PBAT/PHA films by achieving the best retention of $\varepsilon_{\mathrm{b}}$ and $\sigma_{\mathrm{b}}$, this finding is consistent with the best performance of UVA during AAT (Figure 2). Moreover, the retention of $\sigma_{b}$ of PBAT/PHA-UVA film after $100 \mathrm{~h}$ of AAT is almost the same as that after 30 days of degradation in soil. This indicates the potential to use AAT to predict soil degradation results under certain soil test conditions, and our test was conducted in Pudong New district of Shanghai, China, from October to November.

However, the hydrolysis resistance additive (HA) did not exhibit consistent retention of both properties, and the film with AO additive had poorer retention than the PBAT/PHA control film without additive in soil test. This may result from biodegradation during the degradation test in soil, the cleavage of ester bonds by extracellular enzymes of microorganisms may have actually accelerated abiotic hydrolysis [42] which lead to more extensive degradation.

\section{Conclusions}

Poly(butylene adipate-co-terephthalate) (PBAT)/polyhydroxyalkanoate (PHA) biodegradable mulch films were prepared from a series of PBAT/PHA 20/80 wt./wt. blends with or without stabilizers via a twin screw extrusion process. The degradation behaviors of the films were systematically studied under an Accelerated Aging Test (AAT). It was found that adding a low level (20 wt.\%) of PHA to PBAT has substantially decreased the retention of mechanical properties of PBAT.

By studying the effects of a UVA stabilizer, an antioxidant, and a hydrolysis resistance additive, it was found that the UV stabilizer under investigation was the most effective in protecting the PBAT/PHA films. Adding $0.3 \%$ UV stabilizer achieved more than 12 times improvement in mechanical properties. The surface morphology of the PBAT/PHA film without additives had an evolution of staged degradation eventually forming large defects on the film surface, while adding a UV stabilizer effectively inhibited or delayed such damages caused by photodegradation.

Thermal properties, XRD, FTIR, and XPS all provided evidences consistently supporting the trends of mechanical properties. A photodegradation mechanism was proposed for the PBAT/PHA films under accelerated aging conditions, suggesting several types of chain session pathways involving photooxidation and Norrish Type I/II reactions.

Soil degradation test showed that the UV stabilizer was the most effective stabilizer which is consistent with its performance in AAT, this has indicated potential to use AAT to predict the degradation behaviors 
in soil under certain conditions. Overall, this work has provided systematic basis for understanding the photo-degradation behaviors of PBAT/PHA biodegradable mulch films.

\section{Declarations}

\section{Author Contributions}

YT, JW and BZ were involved in the experimental works. YT performed all the experiments and wrote the paper. JW supervised on the establishment of the experiment scheme. BZ helped with the preparation of the films. JW and BZ provided the revision of the whole manuscript.

\section{Acknowledgments}

This research was supported by the National Key Research and Development Program of China (Grant No. 2016YFB0302500). Thanks for the help of Qin Jia for some measurements provided.

\section{Conflicts of interests and availability of data}

The authors declare that the research was conducted in the absence of any commercial or financial relationships that could be construed as a potential conflict of interest.

The datasets generated and analysed during the current study are available from the corresponding author on reasonable request.

\section{References}

1. Liu E, He W, Yan C (2014) 'White revolution' to 'white pollution'-agricultural plastic film mulch in China. Environ Res Lett 9:091001.

2. Halley P, Rutgers R, Coombs S, Kettels J, Gralton J, Christie G, Jenkins M, Beh H, Griffin K, Jayasekara R (2001) Developing biodegradable mulch films from starch-based polymers. Starch-Stärke 53:362367.

3. Jayasekara R, Harding I, Bowater I, Lonergan G. Biodegradability of a selected range of polymers and polymer blends and standard methods for assessment of biodegradation (2005) J Polym Environ 13:231-251.

4. Yan C, He W, Mei X (2010) Agricultural application of plastic film and its residue pollution prevention. Beijing, China: Science Press.

5. Brandi H, Bachofen R, Mayer J, Wintermantel E (1995) Degradation and applications of polyhydroxyalkanoates. Can J Microbiol 41:143-153.

6. Ong S Y, Chee J Y, Sudesh K (2017) Degradation of polyhydroxyalkanoate (PHA): a review. Journal of Siberian Federal University Biology 10(2):21-225. 
7. Bugnicourt E, Cinelli P, Lazzeri A, Alvarez V A (2014) Polyhydroxyalkanoate (PHA): Review of synthesis, characteristics, processing and potential applications in packaging. Express Polymer Letters 8:791-808.

8. Philip S, Keshavarz T, Roy I (2007) Polyhydroxyalkanoates: biodegradable polymers with a range of applications. J. Chem. Technol. Biot 2007;82:233-247.

9. Olivera E R, Arcos M, Naharro G, Luengo J M (2010) Unusual PHA biosynthesis. Plastics from bacteria. City: Springer 133-186.

10. Chen G-Q. (2010) Plastics completely synthesized by bacteria: polyhydroxyalkanoates. Plastics from bacteria. City: Springer 17-37.

11. Wang S, Chen W, Xiang H, Yang J, Zhou Z, Zhu M (2016) Modification and potential application of short-chain-length polyhydroxyalkanoate (SCL-PHA). Polymers;8:273.

12. Chen G-Q, Chen X, Wu F, Chen J (2019) Polyhydroxyalkanoates (PHA) Toward Cost Competitiveness and Functionality. Adv Indust and Eng Polym Res 3:1-7.

13. Bordes P, Hablot E, Pollet E, Averous L (2009) Effect of clay organomodifiers on degradation of polyhydroxyalkanoates. Polym. Degrad. Stabil 94:789-796.

14. Buzarovska A, Grozdanov A, Avella M, Gentile G, Errico M (2009) Poly (hydroxybutyrate-cohydroxyvalerate)/titanium dioxide nanocomposites: A degradation study. J. Appl. Polym. Sci 114:3118-3124.

15. Sridhar V, Lee I, Chun H, Park H (2013) Graphene reinforced biodegradable poly (3-hydroxybutyrateco-4-hydroxybutyrate) nano-composites. Express Polym Lett 7.

16. Wang S, Xiang H, Wang R, Peng C, Zhou Z, Zhu M (2014) Morphology and properties of renewable poly(3-hydroxybutyrate-co-3-hydroxyvalerate) blends with thermoplastic polyurethane. Polym Eng Sci 54:1113-1119.

17. Li Z-J, Shi Z-Y, Jian J, Guo Y-Y, Wu Q, Chen G-Q (2010) Production of poly (3-hydroxybutyrate-co-4hydroxybutyrate) from unrelated carbon sources by metabolically engineered Escherichia coli Metab Eng 12:352-359.

18. Povolo S, Romanelli M G, Basaglia M, Ilieva V I (2013) Corti A, Morelli A, Chiellini E, Casella S. Polyhydroxyalkanoate biosynthesis by Hydrogenophaga pseudoflava DSM1034 from structurally unrelated carbon sources. New Biotechnol 30:629-634.

19. Tanadchangsaeng N, Khanpimai D, Kitmongkonpaisan S, Chobchuenchom W, Koobkokkruad T, Sathirapongsasuti N (2016) Fabrication and characterization of electrospun nanofiber films of PHA/PBAT biopolymer blend containing chilli herbal extracts (capsicum frutescens L.). Int J Food Eng 2.

20. Javadi A, Kramschuster A J, Pilla S, Lee J, Gong S, Turng L S (2010) Processing and characterization of microcellular PHBV/PBAT blends. Polym Eng Sci 50:1440-1448.

21. Beber V C, De Barros S, Banea M D, Brede M, De Carvalho L H, Hoffmann R, Costa A R M, Bezerra E B, Silva I D, Haag K (2018) Effect of babassu natural filler on PBAT/PHB biodegradable blends: an investigation of thermal, mechanical, and morphological behavior. Mater 11:820. 
22. Lin X, Fan X, Li R, Li Z, Ren T, Ren X, Huang T S (2018) Preparation and characterization of PHB/PBAT-based biodegradable antibacterial hydrophobic nanofibrous membranes. Polym. Advan. Technol 29:481-489.

23. Nagarajan V, Misra M, Mohanty A K. (2013) New engineered biocomposites from poly(3hydroxybutyrate-co-3-hydroxyvalerate)(PHBV)/poly(butylene adipate-co-terephthalate) (PBAT) blends and switchgrass: Fabrication and performance evaluation. Ind Crop Prod 42:461-468.

24. Javadi A, Srithep Y, Lee J, Pilla S, Clemons C, Gong S, Turng L-S (2010) Processing and characterization of solid and microcellular PHBV/PBAT blend and its RWF/nanoclay composites. Compos Part A-appl S 41:982-990.

25. Raquez J M, Nabar Y, Narayan R, Dubois $P$ (2008) Novel high-performance talc/poly [(butylene adipate)-co-terephthalate] hybrid materials. Macromol. Mater. Eng 293:310-320.

26. Kijchavengkul T, Auras R, Rubino M, Ngouajio M, Fernandez R T (2008) Assessment of aliphaticaromatic copolyester biodegradable mulch films. Part I: Field study. Chemosphere 71:942-953.

27. Stloukal P, Verney V, Commereuc S, Rychly J, Matisova-Rychlá L, Pis V, Koutny M (2012) Assessment of the interrelation between photooxidation and biodegradation of selected polyesters after artificial weathering. Chemosphere 88:1214-1219.

28. Falcão G A, Almeida T G, Bardi M A, Carvalho L H, Canedo E L (2019) PBAT/organoclay composite films-part 2: effect of UV aging on permeability, mechanical properties and biodegradation. Polym Bull 76:291-301.

29. Dan A, Zhang N, Qiu R, Li C, Wang S, Ni Z (2020) Accelerated biodegradation of p-tert-butylphenol in the Phragmites australis rhizosphere by phenolic root exudates. Environ. Exp. Bot 169:103891.

30. Tsatsaroni E, Eleftheriadis I. UV-absorbers in the dyeing of polyester with disperse dyes (2004) Dyes. Pigments 61:141-147.

31. Jendrossek D. Microbial degradation of polyesters: a review on extracellular poly (hydroxyalkanoic acid) depolymerases (1998) Polym. Degrad. Stabil 59:317-325.

32. Sudesh K, Abe H. Practical guide to microbial polyhydroxyalkanoates (2010) City: ISmithers.

33. Avar L, Bechtold K (1999) Studies on the interaction of photoreactive light stabilizers and UVabsorbers. Prog Org Coat 35:11-17.

34. Zhu S, Chen Y, Tang Y, Li Q, Zhong B, Zeng X, Xie D, Jia Z, Jia D (2019) A novel nanosilica-supported ultraviolet absorber for the preparation of robust biodegradable plastic film with high ultraviolet aging resistance. Polym Composite 40:4154-4161.

35. Souza P M S, Morales A R, Sanchez E M S, Mei L H I (2018) Study of PBAT Photostabilization with Ultraviolet Absorber in Combination with Hindered Amine Light Stabilizer and Vitamin E, Aiming Mulching Film Application. J. Polym Environ 26:3422-3436.

36. Scarfato P, Acierno D, Russo P (2015) Photooxidative weathering of biodegradable nanocomposite films containing halloysite. Polym. Composite; 36:1169-1175. 
37. Mosnáčková K, Šlosár M, Kollár J, Janigová I, Šišková A, Chmela Š, Sikorska W, Perd’ochová D, Gálisová I, Alexy P (2019) Ageing of plasticized poly(lactic acid)/poly(3-hydroxybutyrate)/carbon black mulching films during one season of sweet pepper production. Eur Polym J 114:81-89.

38. Šerá J, Serbruyns L, De Wilde B, Koutný M (2020) Accelerated biodegradation testing of slowly degradable polyesters in soil. Polym Degrad Stabil; 171:109031.

39. Li S, Vert M, Scott G, Gilead D (1995) Degradable polymers: principles and applications. Chapman \& Hall, London:43.

40. Oliveira M, Santos E, Araújo A, Fechine G J, Machado A V, Botelho G (2016) The role of shear and stabilizer on PLA degradation. Polym Test 51:109-116.

41. Kijchavengkul T, Auras R, Rubino M, Selke S, Ngouajio M, Fernandez R T (2011) Formulation selection of aliphatic aromatic biodegradable polyester film exposed to UV/solar radiation. Polym. Degrad. Stabil 96:1919-1926.

42. Stloukal P, Jandikova G, Koutny M, Sedlařík V (2016) Carbodiimide additive to control hydrolytic stability and biodegradability of PLA Polym Test 54:19-28.

43. Allen N, Gardette J-L, Lemaire J (1981) Stabiliser interactions with hindered piperidine compounds in polypropylene: Influence of processing. Polym Degrad Stabil 3:199-208.

44. Ren J (2011) Biodegradable poly (lactic acid): synthesis, modification, processing and applications. City: Springer Science \& Business Media.

45. Jiménez A, Peltzer M, Ruseckaite R. (2014) Poly(lactic acid) science and technology: processing, properties, additives and applications. City: Royal Society of Chemistry.

46. Xing Q, Ruch D, Dubois P, Wu L, Wang W-J (2017) Biodegradable and high-performance poly (butylene adipate-co-terephthalate)-lignin UV-blocking films. ACS Sustainable Chemistry \& Engineering 5:10342-10351.

47. Palsikowski P A, Kuchnier C N, Pinheiro I F, Morales A R (2018) Biodegradation in soil of PLA/PBAT blends compatibilized with chain extender. J Polym Environ 26:330-341.

48. Chen S, Liu Q, Wang H, Zhu B, Yu F, Chen G-Q, Inoue Y (2009) Polymorphic crystallization of fractionated microbial medium-chain-length polyhydroxyalkanoates. Polymer 50:4378-4388.

49. Si P, Zou J, Zhang Y, Ying J, Wang F, Qi Y (2016) The photooxidation aging behavior of PLA/PBAT film. Journal of Functional Materials 22:763-770.

50. Hablot E, Dharmalingam S, Hayes D G, Wadsworth L C, Blazy C, Narayan R (2014) Effect of simulated weathering on physicochemical properties and inherent biodegradation of PLA/PHA nonwoven mulches. J Polym Environ 22:417-429.

51. Pattanasuttichonlakul W, Sombatsompop N, Prapagdee B (2018) Accelerating biodegradation of PLA using microbial consortium from dairy wastewater sludge combined with PLA-degrading bacterium. Int Biodeter Biodegr 132:74-83.

52. Grossetête T, Rivaton A, Gardette J, Hoyle C E, Ziemer M, Fagerburg D, Clauberg H. Photochemical degradation of poly (ethylene terephthalate)-modified copolymer. Polymer 2000; 41:3541-3554. 
53. Kijchavengkul T (2010) Design of biodegradable aliphatic aromatic polyester films for agricultural applications using response surface methodology. Ph.D. Thesis, Michigan State University.

54. Gardette M, Thérias S, Gardette J-L, Murariu M, Dubois P (2011) Photooxidation of polylactide/calcium sulphate composites. Polym Degrad Stabil 96:616-623.

55. Rychlý J, Rychlá L, Stloukal P, Koutný M, Pekařová S, Verney V, Fiedlerová A (2013) UV initiated oxidation and chemiluminescence from aromatic-aliphatic co-polyesters and polylactic acid. Polym Degrad Stabil 98:2556-2563.

56. Zaidi L, Kaci M, Bruzaud S, Bourmaud A, Grohens Y (2010) Effect of natural weather on the structure and properties of polylactide/Cloisite 30B nanocomposites. Polym Degrad Stabil 95:1751-1758.

57. Kijchavengkul T, Auras R, Rubino M, Alvarado E, Montero J R C, Rosales J M (2010) Atmospheric and soil degradation of aliphatic-aromatic polyester films. Polym Degrad Stabil 95:99-107.

\section{Figures}

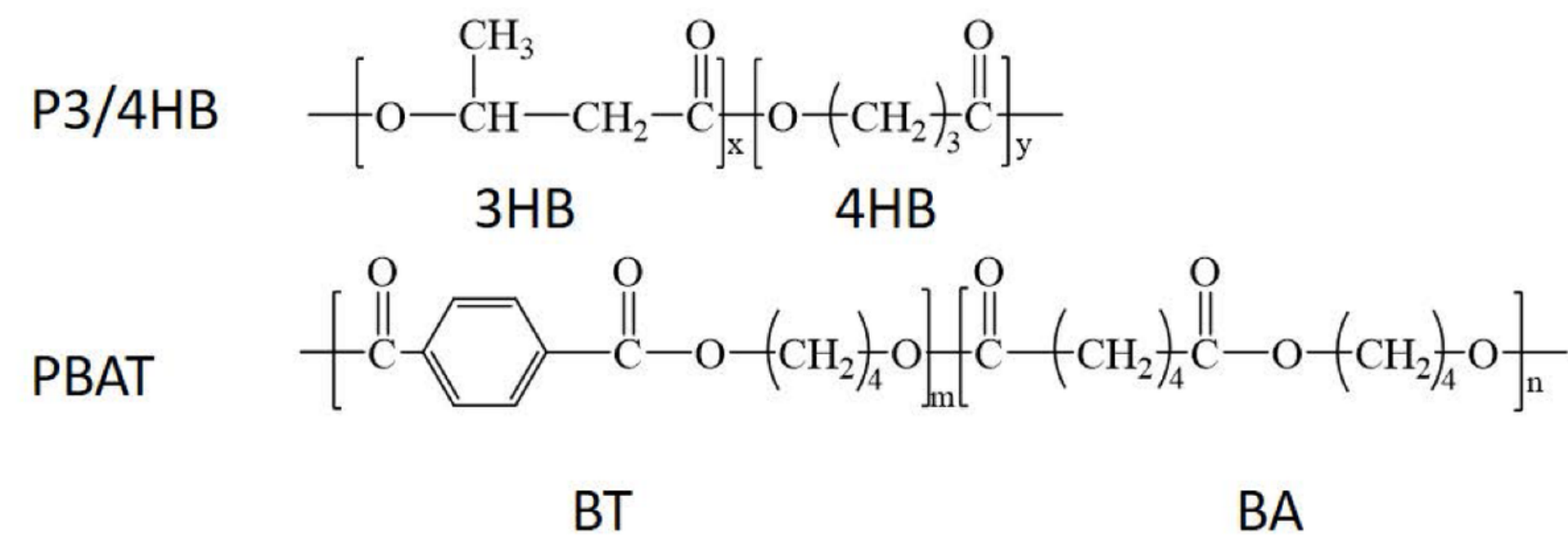

\section{Figure 1}

Chemical structure of poly(3-hydroxybutyrate-co-4-hydroxybutyrate) (P3/4HB) and poly(butylene adipateco-terephthalate) PBAT, with aliphatic butylene adipate (BA) and aromatic butylene terephthalate (BT) domains. 

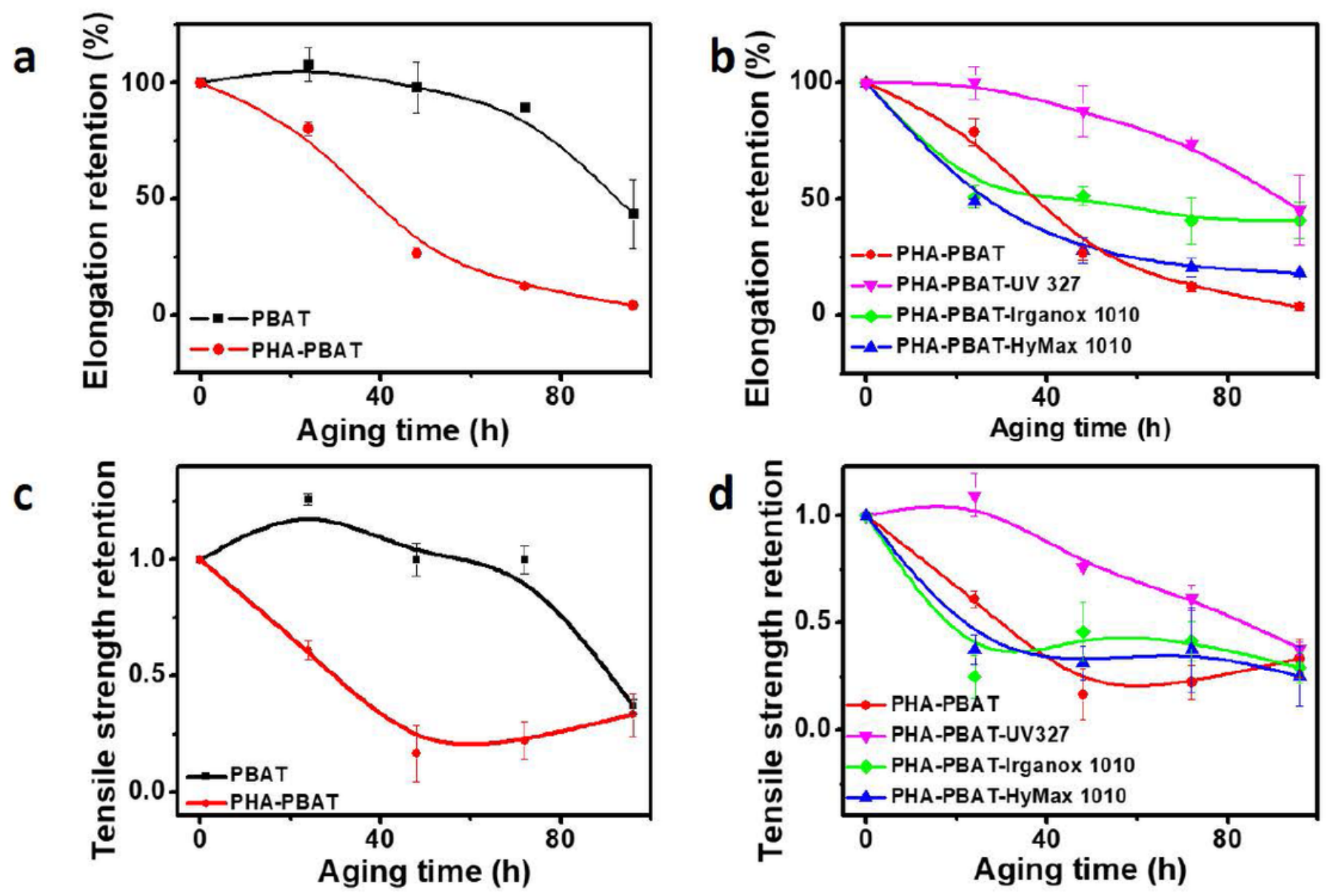

Figure 2

The mechanical performance of PHA-PBAT films after accelerated aging. a and c, Elongation retention (a) and Tensile strength retention (c) of PBAT and PHA-PBAT films after aging; $b$ and $d$, Elongation retention (c) and tensile strength retention (d) of PHA-PBAT with $0.5 \%$ wt different stabilizers after aging. 

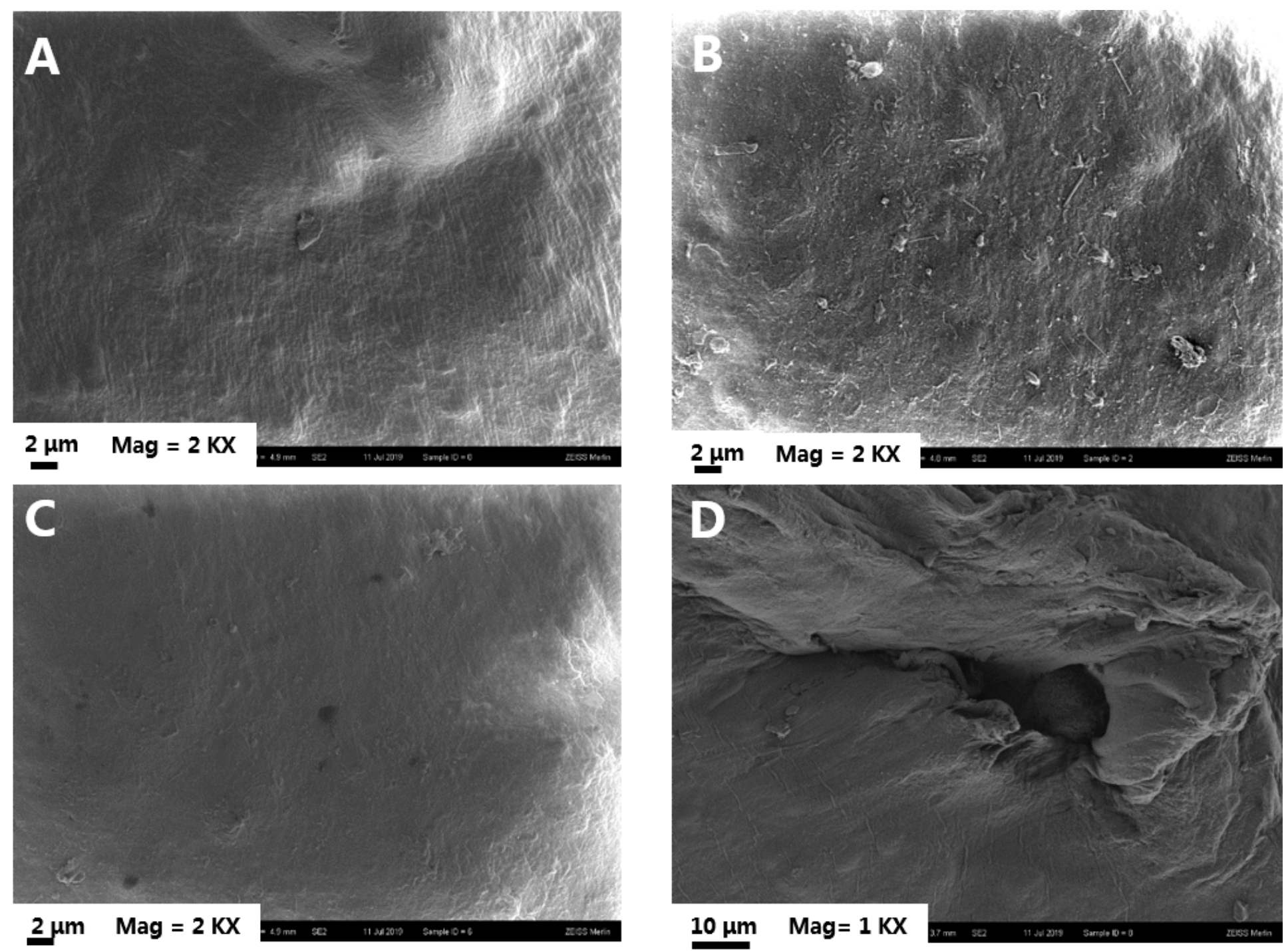

\section{Figure 3}

The morphology of PHA-PBAT after accelerated aging detected by SEM. (a) 0 h, (b) 24 h, (c) 72 h, (d) 100 h. 

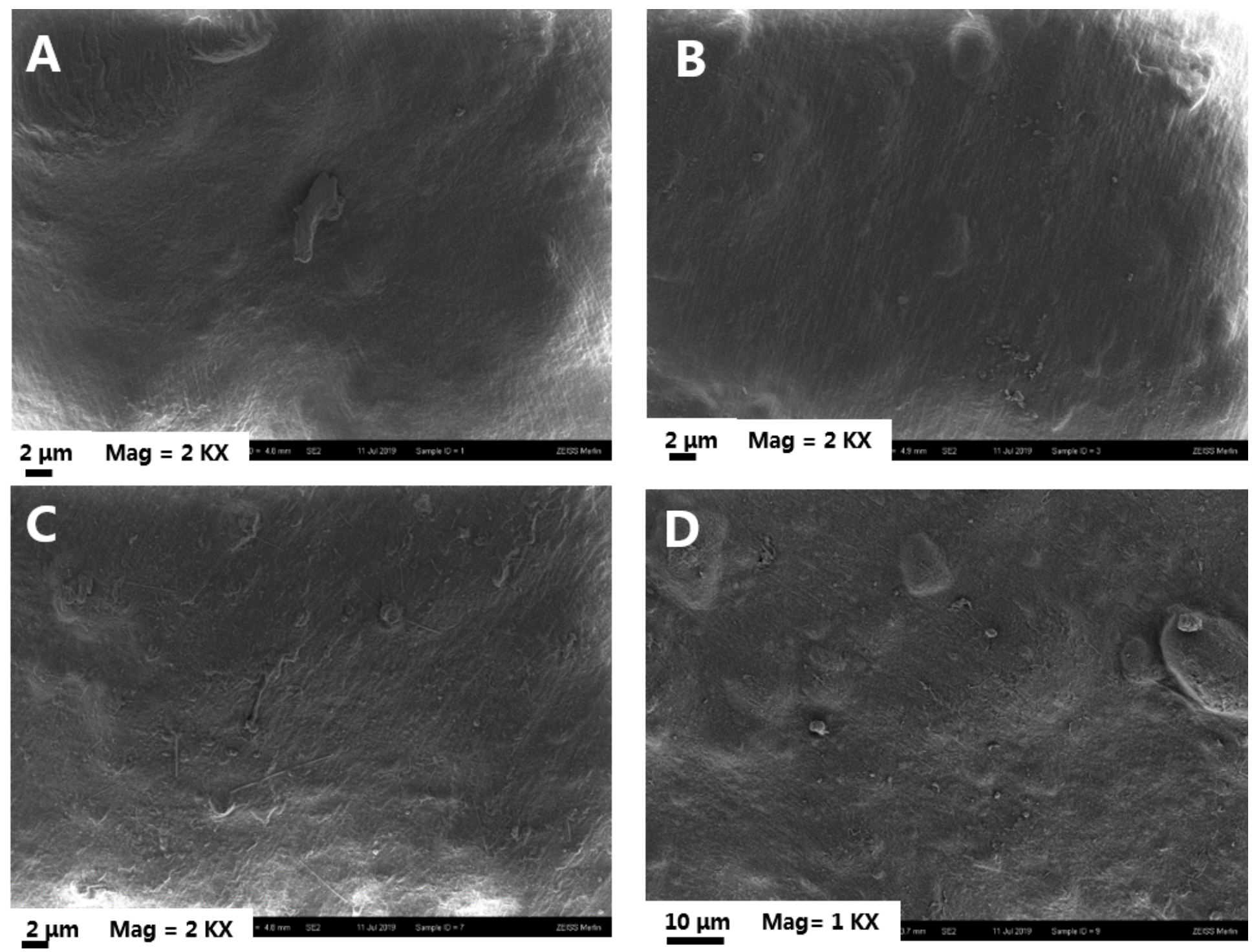

Figure 4

The morphology of PHA-PBAT-UV 327 after accelerated aging detected by SEM. (a) 0 h, (b) 24 h, (c) $72 \mathrm{~h}$, (d) $100 \mathrm{~h}$. 

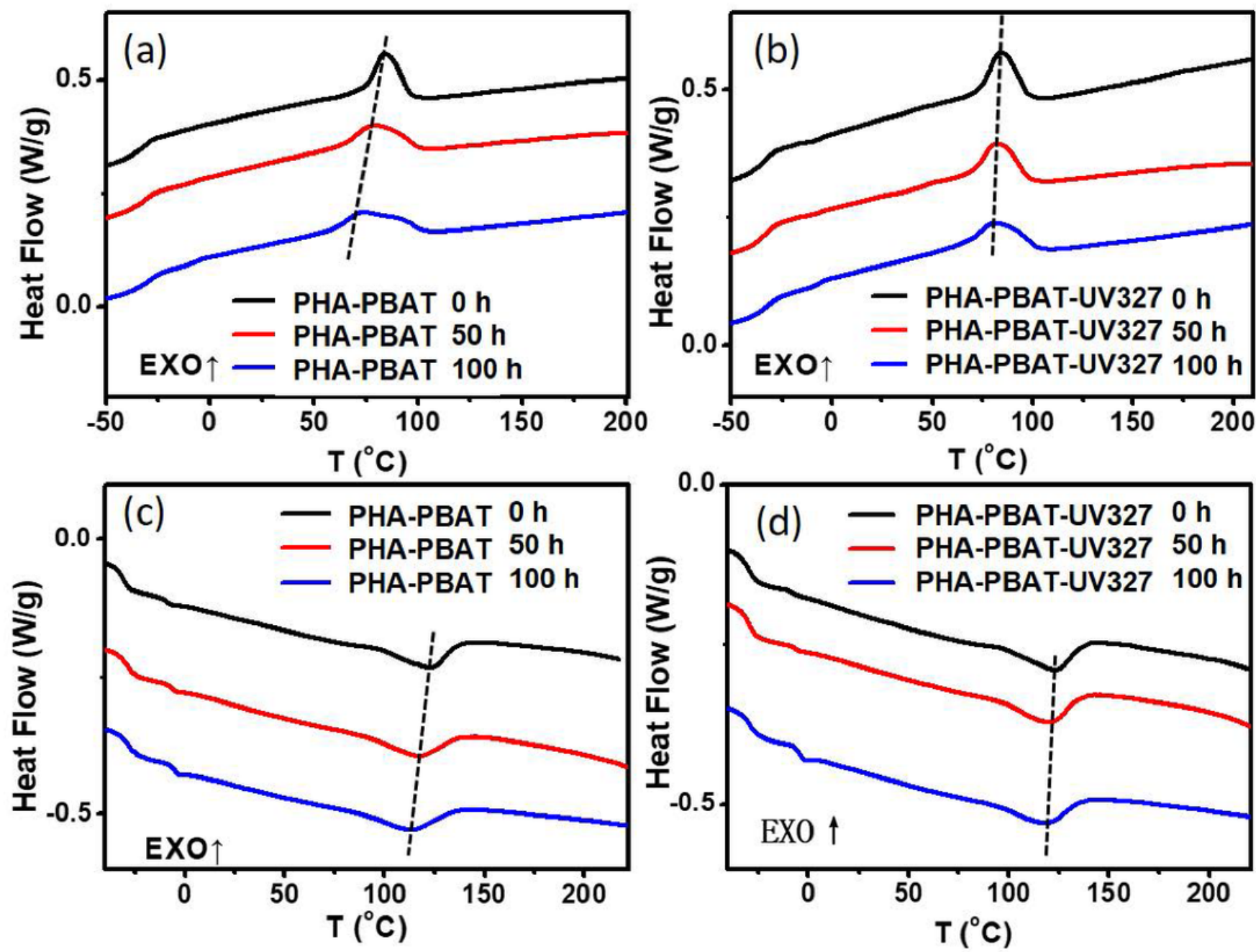

Figure 5

The cooling (a) and second heating (c) DSC curves of PHA-PBAT, and the cooling (b) and second heating (d) PHA-PBAT-UV 327 after accelerated aging.
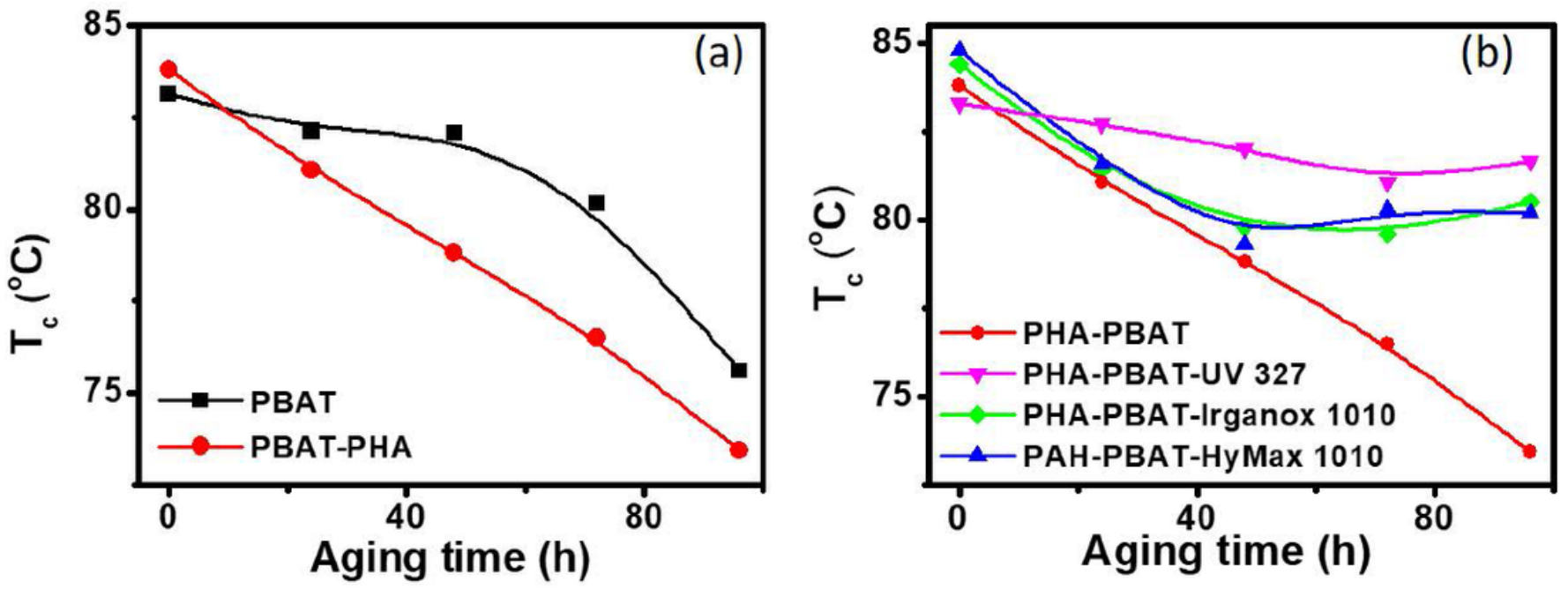
Figure 6

The peak position of Tc of neat PHA-PBAT films (a) and PHA-PBAT with different stabilizers (b) after accelerated aging.
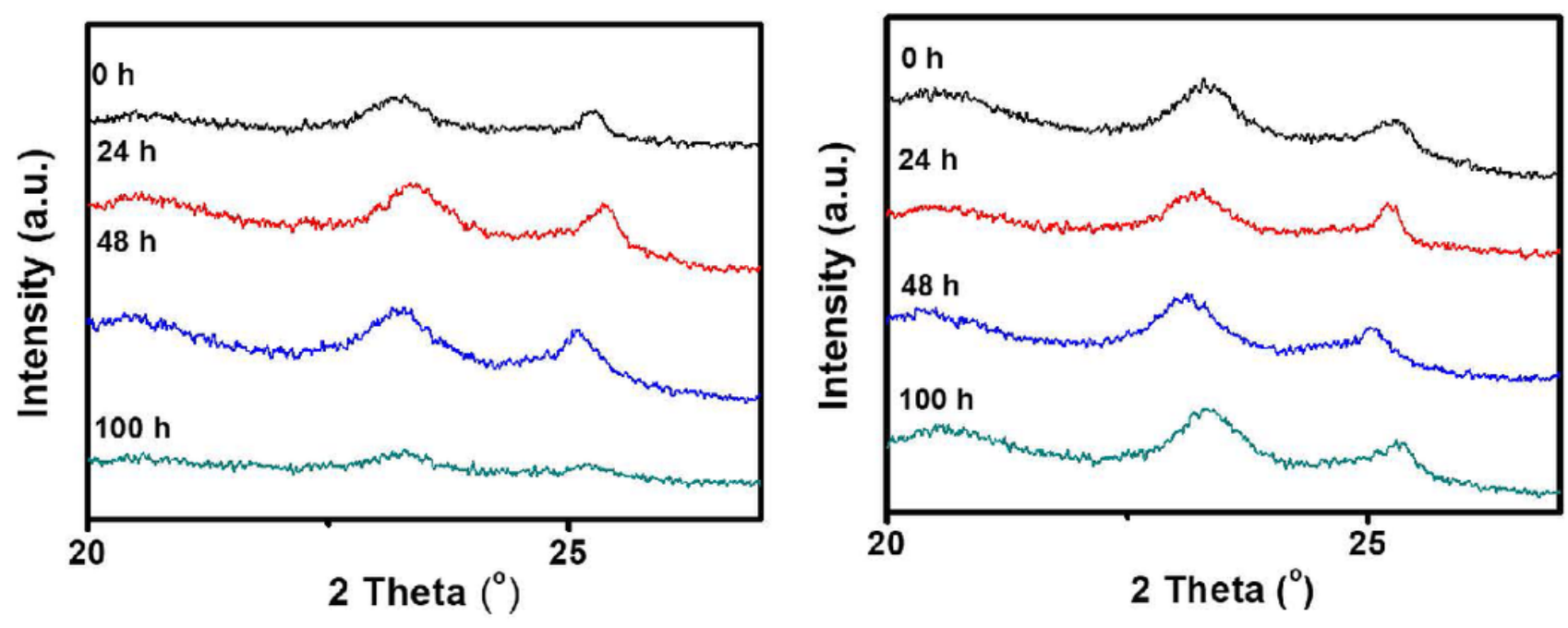

Figure 7

The XRD data of PHA-PBAT (a) and PHA-PBAT-UV 327 (b) after accelerated aging.
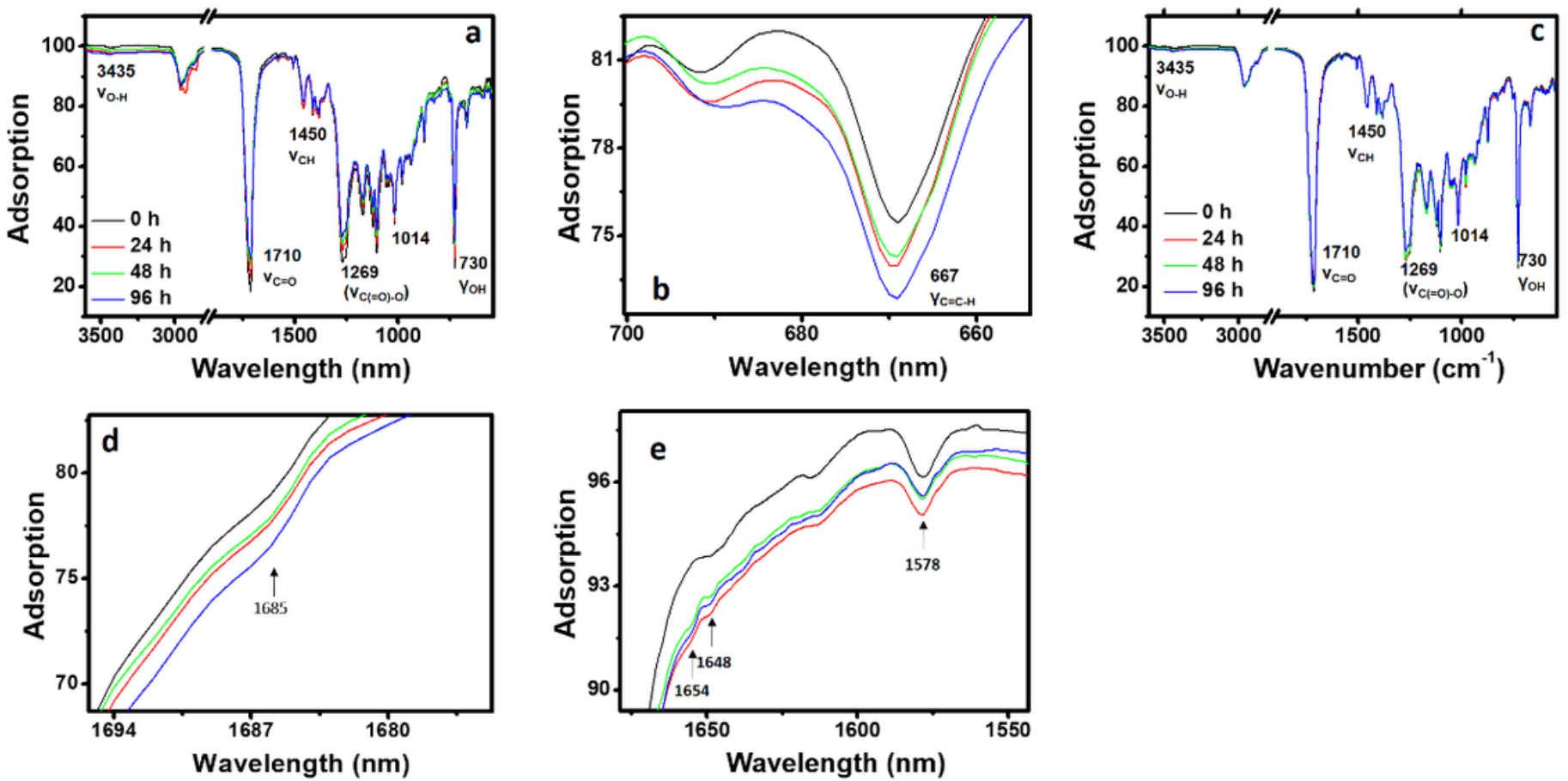

\section{Figure 8}

The ATR-FTIR spectra of PHA-PBAT (a) and PHA-PBAT-UV 327 (c) after accelerated aging, (b), (d), (e) are the enlarged FTIR graph of PHA-PBAT from (a). 

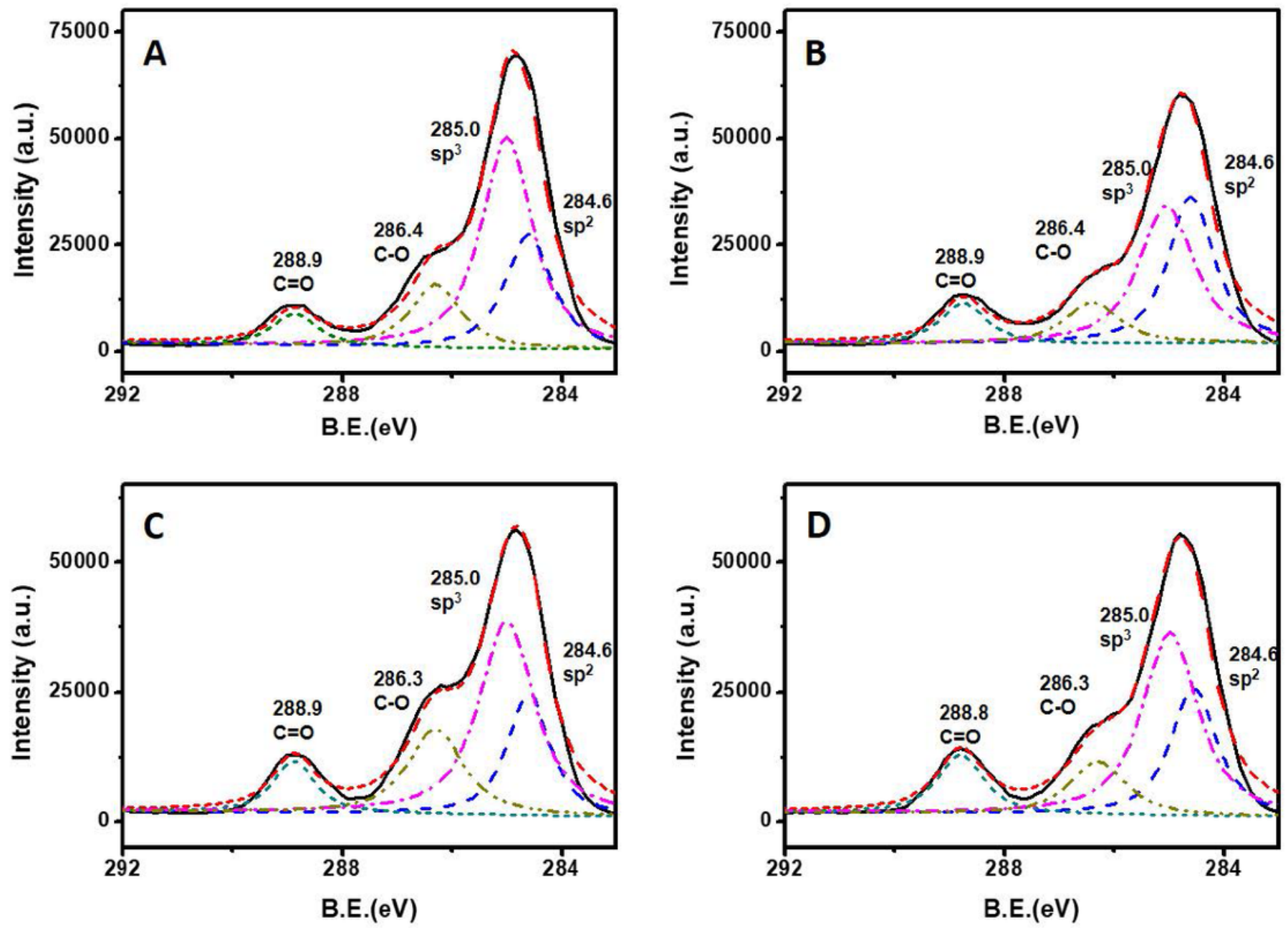

Figure 9

The XPS results of PHA-PBAT before (a) and after (b) accelerated aging and that of PHA-PBAT-UV 327 before (c) and after (d) accelerated 50 hours of accelerated aging.
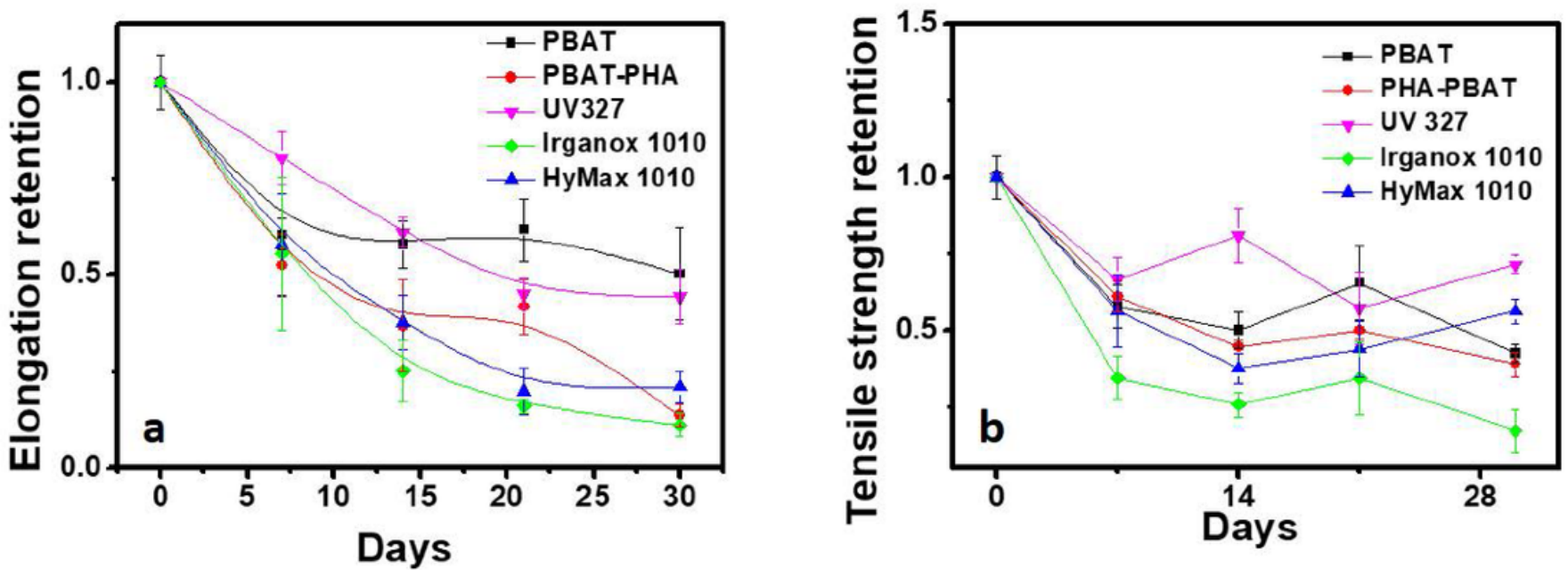

Figure 10 
The mechanical performance of PHA-PBAT films of degradation test in soil, (a) elongation retention, (c) tensile strength retention.

\section{Supplementary Files}

This is a list of supplementary files associated with this preprint. Click to download.

- supplementarymaterial.docx

- schema1.png

- schema2.png 